ORIGINAL PAPER

\title{
THE RELATIONSHIP OF MAST CELL DENSITY IN PULMONARY, GASTRIC AND OVARIAN MALIGNANT EPITHELIAL TUMORS WITH TUMOR NECROSIS AND VASCULARIZATION
}

\author{
Şeyhmus Kaya ${ }^{1}$, Feyzullah Uçmak ${ }^{2}$, Zübeyir BozdaĞ ${ }^{3}$, UĞUr Firat ${ }^{4}$
}

\author{
${ }^{1}$ Department of Pathology, Gazi Yaşargil Education and Research Hospital, Diyarbakır, Turkey \\ ${ }^{2}$ Department of Gastroenterology, Dicle University, Faculty of Medicine, Diyarbakır, Turkey \\ ${ }^{3}$ Department of General Surgery, Faculty of Medicine, Dicle University, Diyarbakır, Turkey \\ ${ }^{4}$ Department of Pathology, Faculty of Medicine, Dicle University, Diyarbakır, Turkey
}

\begin{abstract}
Although many studies have been conducted to explore the relationship between mast cells (MC) and angiogenesis, comparison of this relationship with tumor necrosis has not been investigated to the best of our knowledge. Therefore, the relationship between MC and neovascularization in stomach, lung and ovarian malignant epithelial tumors (165 cases) in necrotizing or non-necrotizing cases was explored in this study. We immunohistochemically studied anti-mast cell tryptase antibody for MC and anti-CD34 antibody for vascular structures. MCs in the intratumoral and peritumoral fields, as well as vascular structures with luminal and monocellular appearances in the intratumoral field, were counted in each sample. Ten magnification fields were analyzed for each sample. In stomach and lung cases, the non-necrotizing group exhibited a greater number of $\mathrm{MC}$ and vascular structures in total. In ovarian cases, more MCs were counted overall in the necrotizing group, but there were fewer vascular structures. The increase in the number of MC and vascular structures in lungs and stomach in the non-necrotizing group supports the theory that MCs are involved in tumor progression. Necrosis, which can be induced on the basis of restricted neovascularization through inhibition of MCs in lung and stomach tumors, may be a treatment method.
\end{abstract}

Key words: malignant epithelial tumor, necrosis, mast cell, vascularization.

\section{Introduction}

Malignant epithelial tumors are an important group of tumors that can develop in many organs including the stomach, ovary, and primarily the lungs, and can cause death. Tumor tissue interacts with surrounding connective tissue elements and inflammatory cells that the immune system produces against the tumor. Mast cells (MC) are found to be one of these inflammatory cellular elements [1]. Mast cells are immune cells found in the bone marrow derived from hematopoietic stem cells (CD34+), all vascularized tissues and in the serous cavities where they reach maturity [2]. Mast cells are of bone marrow origin and have small nuclei and granular cytoplasm [3]. Mast cells are potentially a source of a range of cytokines/chemokines, and act as growth factors involved in both natural and adaptive immune responses mediating allergic disease [4]. Mast cells are effector cells involved in IgE mediated responses, but they can also mediate inflammation after activation by various molecules through Toll-like receptors, interleukin 1 (IL-1) receptors and neurotransmitter receptors without the intervention of IgE. Thus, binding of the antigen to these receptors can also 
activate mast cells without degranulation. There are two types of MCs in humans: mast cell tryptase and mast cell tryptase-chymase [5]. Interleukin 1, IL-18, IL-33 and IL-36 playing an important role in the immune response and inflammation are members of the IL- 1 family cytokines. Cytokines such as TNF and IL-1 are produced by MCs and are also capable of activating mast cells [6]. Their proportions vary in different organs and in different malignant variations $[7,8,9,10]$. The interaction of MCs with cancer tissue has been investigated in many studies. The interaction between MC presence and tumor tissue has been demonstrated in oral malignant and premalignant tumors $[11,12,13$, 14, 15], gastric carcinoma [16], breast carcinoma [17], endometrium carcinoma [18], cervical carcinoma [19] and basal cell carcinoma [20] tumors. Mast cell-associated VEGF [21] allows neovascularization [22] and cancer development [23]. In a study by Hiromatsu and Toda, which supports this condition, it has been reported that MCs are closely associated with angiogenesis or neovascularization, and histopathological examinations suggested an increase in the number of mast cells in areas of angiogenesis [24].

It has been suggested that degranulation of MCs induces tumor growth and spread via certain secreted molecules (angiogenic VEGF, collagenolytic enzymes, etc.), and it has also been shown that MCs inhibit tumor growth and cause tumor cell apoptosis by other secreted molecules such as TNF- $\alpha$ and IL-4 [25]. It is also mentioned that MCs exert an anti-tumor effect by causing cytotoxicity [27]. Although these features of MCs are investigated, it is not yet clear whether the increase in MC concentration causes tumor growth or inhibition, or whether this is caused by a simple defensive reaction [25]. Therefore, the role of MCs in terms of tumor tissue interaction and the changes they cause should be well known.

For these reasons, we aimed to investigate the relationship of MCs with angiogenesis between necrotizing and non-necrotizing groups in stomach, lung, and ovarian malignant epithelial tumors, which are commonly seen in the population. For this, we immunohistochemically compared anti-mast cell tryptase antibody and anti-CD34 antibody expression between necrotizing and non-necrotizing groups. A larger number of MCs and vascular structures in the non-necrotizing group compared to the necrotizing group will support the hypothesis that MCs affect neovascularization positively. This will in turn support the possibility that MCs may induce ischemic necrosis in tumor tissue by inhibition of the mechanism of action on neoangiogenesis. Thus, a new therapeutic approach can be obtained that restricts or prevents tumor tissue development. In the literature, there is no study demonstrating the relationship of MC and neovascularization between necrotizing and non-necrotizing groups.

\section{Material and methods}

For the present study, approval of Dicle University Medical Faculty Ethics Committee was obtained with protocol number 81-23.01.2015. Hospital records of the stomach, lung and ovarian resection materials and relevant preparations of the patients who were admitted to Diyarbakır Dicle University Faculty of Medicine, Pathology Department between 2006 and 2015 were examined by looking at the records. Cases diagnosed with malignant epithelial tumor were included in the study. All hematoxylin and eosin (HE) stained slides of the studied cases were re-examined by an expert pathologist for confirmation of diagnosis. Histological classification was based on the latest World Health Organization (WHO) classification. As a result of these investigations, a total of 165 malignant epithelial tumors ( 50 stomach, 56 lung, 59 ovarian) to be included in this study were detected. The cases were divided into two groups: necrotizing (necrosis + ) and non-necrotizing (necrosis-).

\section{Immunohistochemical staining}

Tissues suitable for immunohistochemical examination were identified in HE stained slides, and the paraffin blocks in the archives of our department were accessed. Two $5 \mu \mathrm{m}$-thick sections were prepared on positively charged slides from each of the identified paraffin blocks. These preparations were dried in an incubator at $56^{\circ} \mathrm{C}$ for one hour and the sections were allowed to stick to the slide. Immunohistochemical staining was automatically performed on the Ventana Benchmark XT device (Ventana, Tucson, AZ), as appropriate for the device kit manual. Control blocks were first identified for proper immunohistochemical evaluation. For the anti-CD34 antibody, paraffin blocks containing tonsil tissue evaluated in our unit, and for the anti-mast cell tryptase antibody, paraffin blocks containing mastocytosis-diagnosed skin tissue were selected as the control blocks. Using these control blocks, it was determined whether the readyto-use CD34 antibody worked, and in which dilution the anti-mast cell typing antibody (dilution type antibody) worked best. The preparations of all cases treated with immunohistochemical staining were examined under light microscopy. MCs were counted in intratumoral (IT) and peritumoral (PT) localization in 10 fields (using $40 \times$ magnification) showing the best positive staining by anti-mast cell tryptase antibody (clone: $1 \mathrm{~A} 1, \mathrm{DAKO}$, at a dilution rate of $1 / 300$, with an incubation time of $0 \mathrm{~h} 44 \mathrm{~min}$; Fig. 1-3). Vascular structures with monocellular and lumen appearance were counted in IT localization in 10 fields (using $40 \times$ magnification) showing the best positive staining by anti-CD34 antibody (clone; QBEnd/10, VENTANA/ ROCHE, ready-to-use form, with an incubation time of 0 h 32 min; Fig. 1-3). 

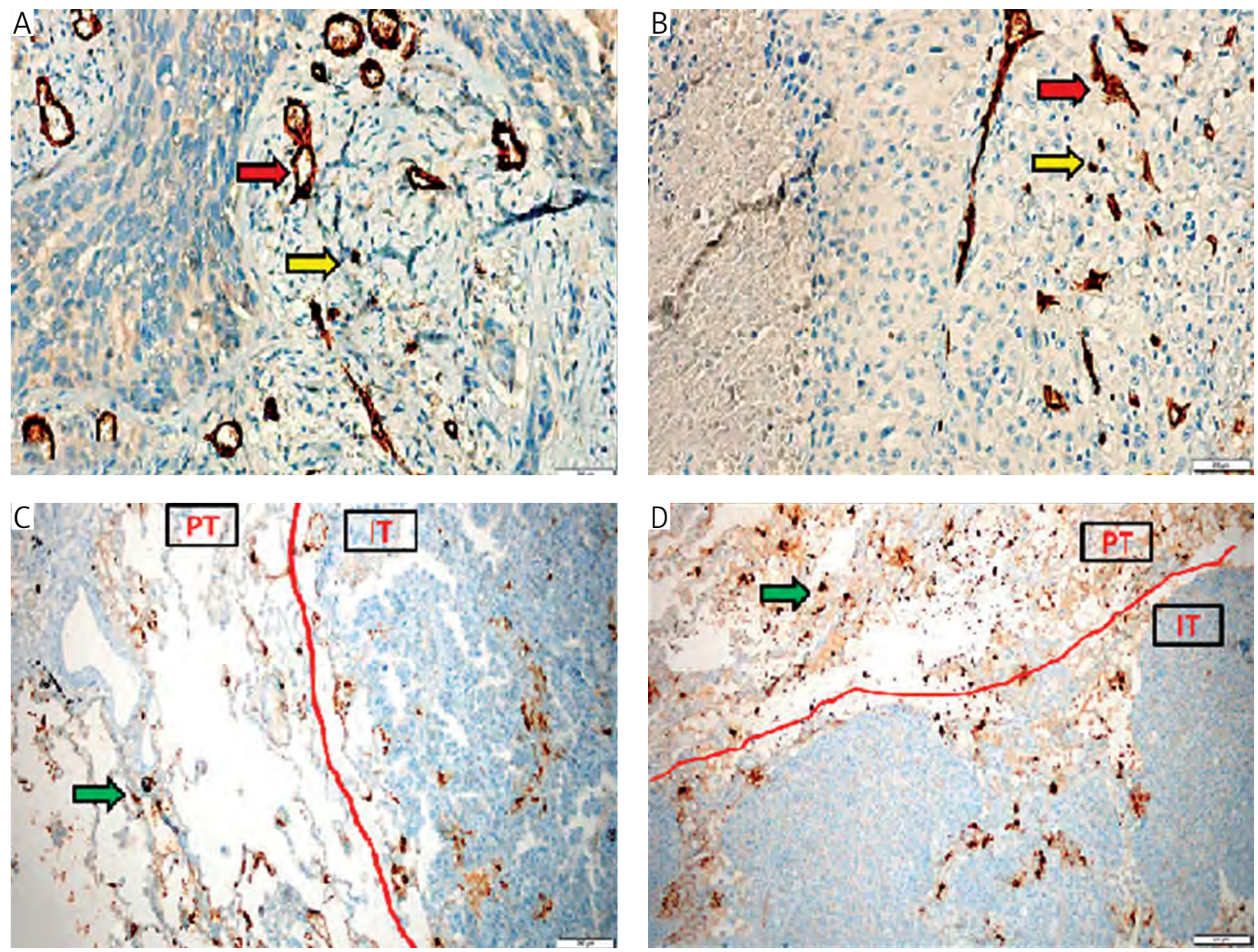

Fig. 1. Lung tissue. A) Structures with lumen (red arrow) and single cell formation (yellow arrow) stained with CD34 in the necrosis negative, intratumoral (IT) area $(\times 400)$. B) Structures with lumen (red arrow) and single cell formation (yellow arrow) in the necrosis positive, IT area $(\times 400)$. C) Mast cells (green arrow) $(\times 200)$ stained with mast cell tryptase in tissue separating necrosis negative, peritumoral (PT) and IT area indicated with red line. D) Mast cells (green arrow) $(\times 200)$ stained with mast cell tryptase in tissue separating necrosis positive, PT and IT area indicated with red

Statistical evaluation of the obtained data was performed through the statistical package program SPSS for Windows 15.0 (SPSS Inc., Chicago). Chisquare analysis was used to compare categorical data. The Kolmogorov-Smirnov test was used to check whether numerical data were normally distributed. Those with normal distribution were analyzed with one-way ANOVA (Tukey test) and Student's t test, while those with non-normal distribution were analyzed with the Kruskal-Wallis test and Mann-Whitney $U$ test. It was found that the difference was statistically significant with a $\mathrm{p}$ value $<0.05$.

\section{Results}

Male/female (M/F) ratio in stomach and lung cases was 2.1 and 6.0 respectively. The mean age of stomach, lung and ovarian cases was $61.54 \pm 12.68,58.02$ \pm 13.26 , and $54.37 \pm 15.85$, respectively. Mean tumor size in stomach, lung, and ovarian cases was 5.23 $\pm 2.23,4.65 \pm 2.46$, and $7.28 \pm 4.38$, respectively.
The number and percentage of cases with and without necrosis in organs are shown in Table I. The number of cases without necrosis in gastric tumors is approximately 3 times the number of cases with necrosis. The numbers of cases with and without necrosis are similar for lung and ovary. While the number of cases without necrosis is higher than the number of cases with necrosis in gastric and ovarian cases, the opposite is the case in lung cases.

Anti-mast cell tryptase antibody and anti-CD34 antibody staining and statistical data of three organs are shown in Table II. In the gastric, lung and ovarian cases, mast cells are present in the intratumoral and peritumoral areas. In the gastric and lung cases, the group without necrosis contained more mast cells and vascular structures in total. In the ovarian cases, more mast cells but fewer vascular structures were counted in the group with necrosis. In addition, structures with a lumen in the intratumoral area were more common in all organs than vascular structures with a single-cell appearance. In the group without 

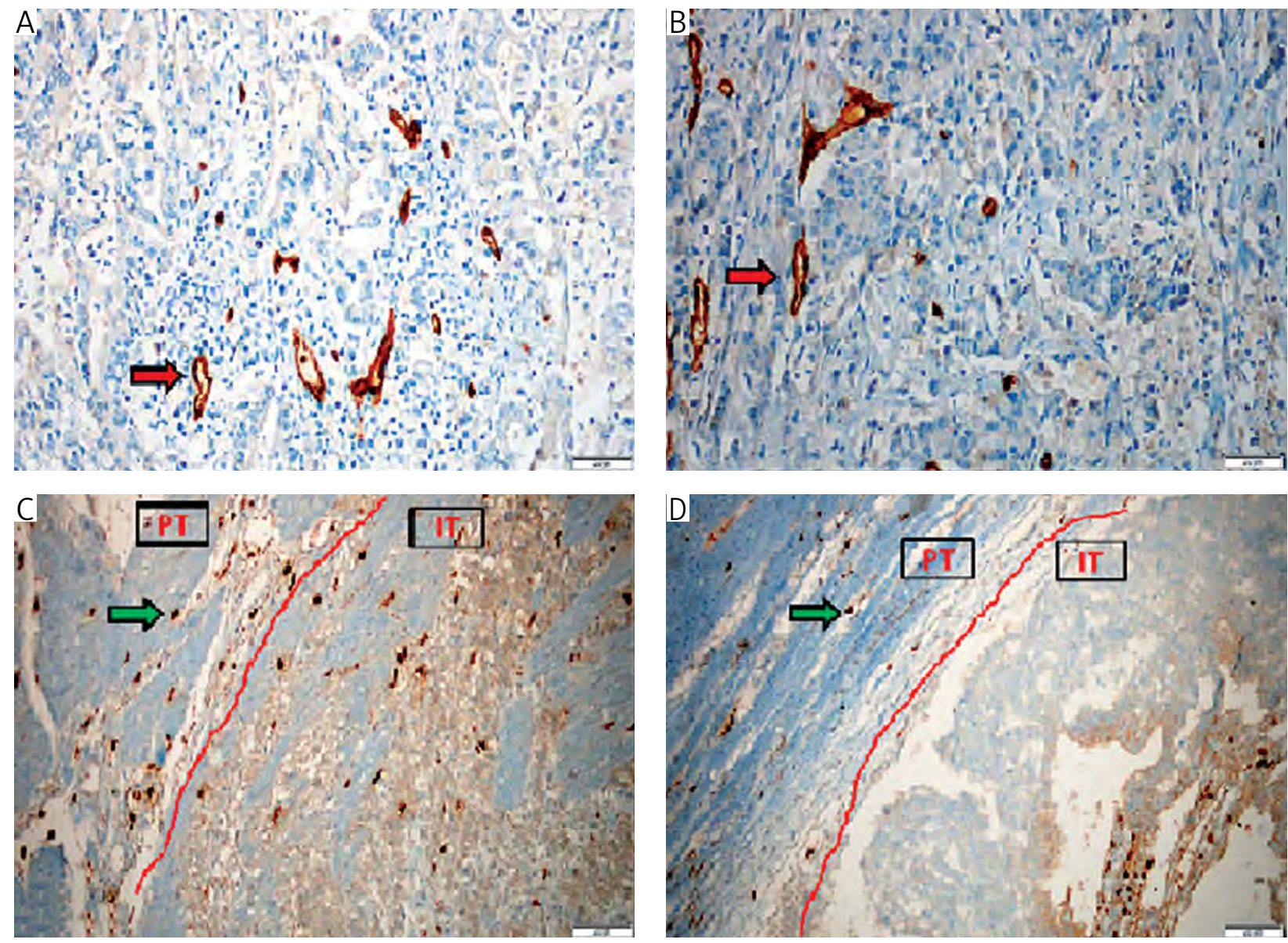

Fig. 2. Gastric tissue. A) Structures with lumen (red arrow) and single cell formation (yellow arrow) stained with CD34 in the necrosis negative, intratumoral (IT) area $(\times 400)$. B) Structures with lumen (red arrow) and single cell formation (yellow arrow) in the necrosis positive, IT area $(\times 400)$. C) Mast cells (green arrow) $(\times 200)$ stained with mast cell tryptase in tissue separating necrosis negative, peritumoral (PT) and IT area indicated with red line. D) Mast cells (green arrow) $(\times 200)$ stained with mast cell tryptase in tissue separating necrosis positive, PT and IT area indicated with red line

necrosis, the vascular structures with a single-cell appearance in the intratumoral area were more common and significantly higher.

\section{Discussion}

Our findings support the theory that MCs induce neoangiogenesis since we found that there were more MCs and vascular structures in non-necrotizing cases in lung and stomach tumors. However, this relationship is absent in ovarian tumors.

A clear and precise understanding of the tumor growth mechanism is highly important. It is vital for prevention of tumor development and treatment. So far, many scientific studies have contributed to this process. With the definition of microenvironment in the 1980s, the interaction of cancer tissue and normal surrounding tissue has become a hot topic. MCs are one of the cellular elements that can be found in the tumor microenvironment. However, it is difficult to recognize MCs in the histomorphological evaluation of tumors. To make MCs visible, tolui- dine blue can be used histochemically, and anti-mast cell tryptase and anti-CD117 antibodies can be used immunohistochemically. In our study, we used antimast cell tryptase antibody to stain MCs.

In some studies in the relevant field, researchers used MC/tumor ratio to determine tissue mast cell density (MCD), while others accepted $\geq 20$ under $10 \times$ magnification of tissue sample [27], or $>3$ detected in every 30 immersion levels under high magnification (40× objective) as a high MC count [28]. In our study, we considered the number of mast cells instead of mast cell density. We evaluated total mast cell count as IT and PT by counting 10 fields with $40 \times$ magnification. There is no study in the literature analyzing the superiority of existing methods over each other. We believed that specifying the number of cells would give a better result.

Studies conducted by Ying-An Jiang et al. [29] and Açlkalın et al. [30] showed no significant relationship between tumor size and mast cell density. In our study, the relationship between tumor size and MC number was not evaluated. 

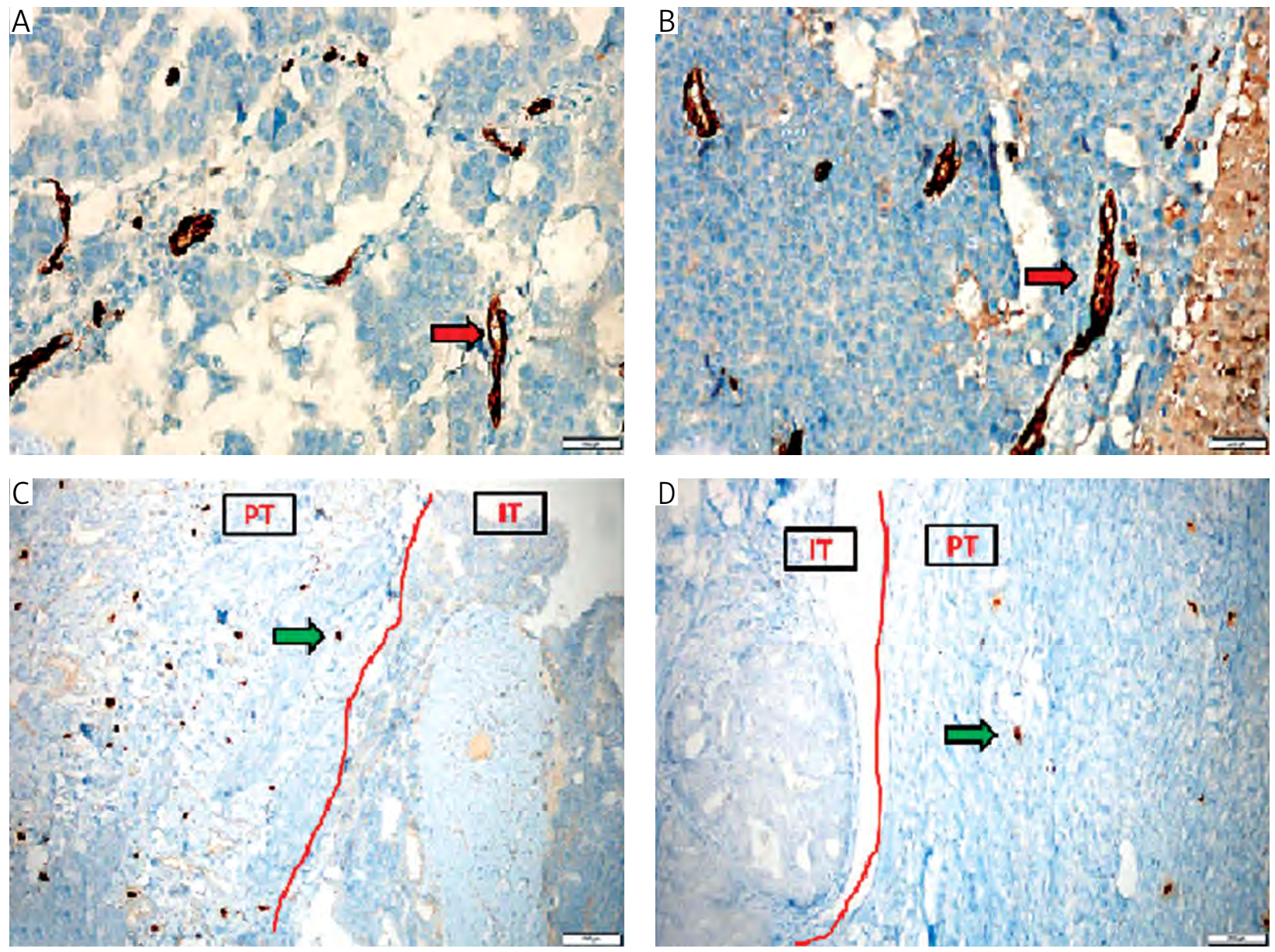

Fig. 3. Ovarian tissue. A) Structures with lumen (red arrow) and single cell formation (yellow arrow) stained with CD34 in the necrosis negative, intratumoral (IT) area $(\times 400)$. B) Structures with lumen (red arrow) and single cell formation (yellow arrow) in the necrosis positive, IT area $(\times 400)$. C) Mast cells (green arrow) $(\times 200)$ stained with mast cell tryptase in tissue separating necrosis negative, peritumoral (PT) and IT area indicated with red line. D) Mast cells (green arrow) $(\times 200)$ stained with mast cell tryptase in tissue separating necrosis positive, PT and IT area indicated with red line

Neoangiogenesis is essential for tumor growth and spread. When the tumor size exceeds $0.5 \mathrm{~mm}^{3}$, tumor nourishment is dependent on angiogenesis. Tumors smaller than $0.5 \mathrm{~mm}^{3}$ can obtain oxygen and nutrients via diffusion [31]. For this reason, in tumors larger than $0.5 \mathrm{~mm}^{3}$, if neoangiogenesis does not occur, the existing tumoral tissue nutrition will be restricted and necrosis and cell death will occur in tumor tissue as a result of hypoxia. Cell injury and necrotic substances will perform the collection of inflammatory cells into this area after many complex processes. Mast cells, one of the inflammatory cells, are effector cells involved in IgE-mediated responses (with FceRI on their surface), also after activation by various molecules via Toll-like receptors, interleukin 1 (IL-1) receptors and neurotransmitter receptors without the interference of $\operatorname{IgE}$ can also mediate inflammation [5]. Thus, they can be activated by a series of stimuli, both via the FceRI receptor on the mast cell surface and via receptors other than the Fc\&RI receptor $[2,3,4,5,6]$. Interleukin 1 pro-
Table I. Number and ratios of necrosis-positive and necrosis-negative cases in gastric, lung, and ovarian malignant epithelial tumors

\begin{tabular}{llccc}
\hline \multicolumn{5}{c}{ Necrosis } \\
\hline Organ & & Negative & Positive & Total \\
\hline Stomach & Number & 38 & 12 & 50 \\
& $\%$ & 76.0 & 24.0 & 100 \\
\hline Lung & Number & 26 & 30 & 56 \\
& $\%$ & 46.4 & 53.6 & 100 \\
\hline Ovary & Number & 33 & 26 & 59 \\
& $\%$ & 55.9 & 44.1 & 100 \\
\hline Total & Number & 97 & 68 & 165 \\
& $\%$ & 58.8 & 41.2 & 100 \\
\hline
\end{tabular}

duced by MCs also has the ability to activate mast cells [6]. Neoangiogenesis is stimulated by some substances released by activated mast cells [26]. With 
neoangiogenesis, tumor tissue can be fed adequately and avoids necrosis due to hypoxia. With sufficient angiogenesis, the tumor can grow rapidly and have the ability to metastasize to close or long distances. Clinical data suggest that metastatic potential and prognosis are related to the severity of angiogenesis. Therefore, the current level of angiogenesis needs to be determined. Some methods used in this regard include detection of microvessel density, measurement of angiogenic factors in blood and urine, and determination of tissue levels of angiogenic proteins. In our study, we determined the increase in angiogenesis by counting the vascular structures with luminal and monocellular appearance in the IT field. To visualize vascular structures, we performed immunohistochemical anti-CD34 antibody staining.

It has been proposed that tryptase secreted by MCs breaks down the connective tissue to open the necessary area for neoangiogenesis and is a potent angiogenic stimulant [32]. Many studies in the literature support this hypothesis. In one, mast cell concentration in the intratumoral and peritumoral area and microvessel density in oral squamous cell carcinoma were compared using immunohistochemical markers (anti-CD31 antibody, anti-tryptase antibody). The authors found a statistically significant increase in mast cell concentration and microvessel density relative to normal mucosa in the IT and PT fields [33]. In another study on odontogenic tumors, a significant correlation was found between MCs and microvessels in odontogenic tumors [34]. In a study investigating angiogenesis and mast cell density in relation to the clinical behavior and morphological characteristics of pheochromocytomas, the difference between benign and malignant cases was not significant but vascular structures were correlated with mast cell counts [35]. A direct correlation was found between MCD and angiogenesis during tumor growth in esophagus, lung cancer, and melanoma, and this was thought to be important in prognosis [36]. In our study, non-necrotizing cases contained more MCs and vascular structures in gastric and lung malignant epithelial tumors compared to necrotizing cases. This finding strongly supports the positive effect of MCs on neovascularization.

Some mediators secreted by MCs (chymosin, granzyme, TNF- $\alpha$, IL- 4 , etc.) suppress tumor growth. For example, $\mathrm{MC}$ expression has been shown to increase in several types of cancer, such as breast, ovary, lung, and colorectal carcinoma, and to accompany good prognosis. Furthermore, it has been argued that MCD can inhibit proliferation and spread of tumors in gastric cancer, breast cancer, and soft tissue sarcomas. Higher MCD has been reported to be a good prognostic marker in invasive breast cancer and prostate cancer [37]. In our study, there were more mast cells in the necrotizing group of ovarian cases. 
However, more vascular structures were counted in the non-necrotizing group. This finding supports the hypothesis that MCs suppress tumor growth.

There are certain limitations of this study. More MCs and vascular structures were counted in the lung and stomach cases compared to ovarian cases. The limitation regarding the evaluation of tumor stroma due to more abundant necrotic material in tumors and dense glandular structures in tumor tissue observed in microscopic examination of ovarian cases may explain this difference. In addition, although 10 large magnification fields were counted in each sample, fewer PT fields in some cases compared to other tissues may have affected the number of existing mast cells and vascular structures. Mean tumor sizes were not compared between necrotizing and non-necrotizing groups. For this reason, it is not possible to comment on the relationship between vascular structure, MC count and tumor size.

While new methods and treatment methods are being investigated every day in tumor therapy, it can be seen that inhibition of angiogenesis via mechanisms related to tumor angiogenesis is a topic of high interest. A much better understanding of this topic through further and extensive research can open new horizons in tumor treatment.

The relationship between MCs and neoangiogenesis has been investigated in many types of tumors. However, there is no study investigating this relationship in tumors between necrotizing and non-necrotizing groups. In this regard, our study is the first in the literature. In conclusion, our findings have demonstrated that the increase in number of MCs in the IT and PT fields in the non-necrotizing group in stomach and lung cases accompanied an increase in the number of vascular structures in the tumor tissue. Based on this finding, we believe that ischemic necrosis can be induced, limiting or inhibiting neoangiogenesis in tumor tissue on the basis of $\mathrm{MH}$ inhibition, especially in lung and gastric malignant epithelial tumors. If this can be achieved, we believe that a novel approach for tumor treatment can be developed.

\section{The authors declare no conflict of interest.}

\section{References}

1. Maltby S, Khazaie K, McNagny KM. Mast cells in tumor growth: angiogenesis, tissue remodeling and immune-modulation. Biochim Biophys Acta 2009; 1796: 19-26.

2. Antonopoulos D, Tsilioni I, Balatsos NAA, et al. The mast cell neurofibromatosis connection. J Biol Regul Homeost Agents 2019; 33: 657-659.

3. de Noronha Santos Netto J, Pires FR, da Fonseca EC, et al. Evaluation of mast cells in periapical cysts, dentigerous cysts, and keratocystic odontogenic tumors. J Oral Pathol Med 2012; 41: 630-636.
4. Conti P, Lessiani G, Kritas SK, et al. Mast cells emerge as mediators of atherosclerosis: Special emphasis on IL-37 inhibition. Tissue Cell 2017; 49: 393-400.

5. Taracanowa A, Tsilioni I, Conti P, et al. Substance P and IL-33 administared together stimulate a marked secretion of IL- $1 \beta$ from human mast cells, inhibited by methoxyluteolin. Proc Natl Acad Sci USA 2018; 115: E9381-E9391.

6. Gallenga CE, Pandolfi F, Caraffa Al, et al. Interleukin-1 family cytokines and mast cells: activation and inhibition. J Biol Regul Homeost Agents 2019; 33: 1-6.

7. Karaca T. ve Yörük M. 2005 Mast Hücre Heterojenitesi. YYÜ Vet Fak Derg 2005; 16: 57-60.

8. Dvorak AM. Human mast cells. Adv Anat Embryol Cell Biol 1989; 114: 1-107.

9. Galli SJ. New insights into "the riddle of the mast cells": microenvironmental regulation of mast cell development and phenotypic heterogeneity. Lab Invest 1990; 62: 5-33.

10. Galli SJ. New concepts about the mast cell. N Engl J Med 1993; 328: 257-265.

11. Weidner N, Austen KF. Ultrastructural and immunohistochemical characterization of normal mast cells at multiple body sites. J Invest Dermatol 1991; 96: 26S-31S.

12. Cheema VS, Ramesh V, Balamurali PD. The Relevance of mast cells in oral squamous cell carcinoma. J Clin Diagn Res 2012; 6: 1803-1807.

13. Jahanshahi G, Sabaghian M. Comparative immunohistochemical analysis of angiogenesis and mast cell density in oral normal mucosa and squamous cell carcinoma. Dent Res J (Isfahan) 2012; 9: 8-12.

14. Kalra M, Rao N, Nanda K, et al. The role of mast cells on angiogenesis in oral squamous cell carcinoma. Med Oral Patol Oral Cir Bucal 2012; 17: 190-196.

15. Sharma B, Sriram G, Saraswathi TR, Sivapathasundharam B. Immunohistochemical evaluation of mast cells and angiogenesis in oral squamous cell carcinoma. Indian J Dent Res 2010; 21: $260-265$

16. Michailidou EZ, Markopoulos AK, Antoniades DZ. Mast cells and angiogenesis in oral malignant and premalignant lesions. Open Dent J 2008; 2: 126-132.

17. Ribatti D, Guidolin D, Marzullo A, et al. Mast cells and angiogenesis in gastric carcinoma. Int J Exp Pathol 2010; 91: 350-356.

18. della Rovere F, Granata A, Familiari D, et al. Mast cells in invasive ductal breast cancer: different behavior in high and minimum hormone-receptive cancers. Anticancer Res 2007; 27: $2465-2471$

19. Ribatti D, Finato N, Crivellato E, et al. Neovascularization and mast cells with tryptase activity increase simultaneously with pathologic progression in human endometrial cancer. Am J Obstet Gynecol 2005; 193: 1961-1965.

20. Benítez-Bribiesca L, Wong A, Utrera D, Castellanos E. The role of mast cell tryptase in neoangiogenesis of premalignant and malignant lesions of the uterine cervix. J Histochem Cytochem 2001; 49: 1061-1062.

21. Donelan J, Boucher W, Papadopoulou N, et al. Corticotropin-releasing hormone induces skin vascular permeability through a neurotensin-dependent process. Proc Natl Acad Sci USA 2006; 103: 7759-7764.

22. Vanconcelos RAT, Guimaraes CP, Vieira TM, et al. Prognostic significance of mast cell and microvascular densiities in malignant peripheral nerve sheath tumor with and withouth neurofibromatosis type 1. Cancer Med 2019; 8: 972-981.

23. Ribatti D, Crivellato E, Roccaro AM, et al. Mast cell contribution to angiogenesis related to tumour progression. Clin Exp Allergy 2004; 34: 1660-1664.

24. Erkiliç S, Erbağci Z. The significance of mast cells associated with basal cell carcinoma. J Dermatol 2001; 28: 312-315.

25 . Hiromatsu Y, Toda S. Mast cells and angiogenesis. Microsc Res Tec 2003; 60: 64-69. 
26. Roche WR. The nature and significance of tumour-associated mast cells. J Pathol 1986; 148: 175-182.

27. Achen MG, McColl BK, Stacker SA. Focus on lymphangiogenesis in tumor metastasis. Cancer Cell 2005; 7: 121-127.

28. Ueda T, Aozasa K, Tsujimoto M, et al. Prognostic significance of mast cells in soft tissue sarcoma. Cancer 1988; 62: 24162419.

29. Nechushtan H, Razin E. Regulation of mast cell growth and proliferation. Crit Rev Oncol Hematol 1996; 23: 131-150.

30. Jiang YA, Zhang YY, Luo HS, Xing SF. Mast cell density and the context of clinicopathological parameters and expression of p185, estrogen receptor, and proliferating cell nuclear antigen in gastric carcinoma. World J Gastroenterol 2002; 8: 1005-1008.

31. Acikalin MF, Oner U, Topçu I, et al. Tumour angiogenesis and mast cell density in the prognostic assessment of colorectal carcinomas. Dig Liver Dis 2005; 37: 162-169.

32. Konukoğlu D. Anjiyogenezin temel moleküler mekanizmaları ve tümör anjiyogenezi. Cerrahpaşa J Med 2005; 36: 42-48.

33. Blair RJ, Meng H, Marchese MJ, et al. Human mast cells stimulate vascular tube formation. Tryptase is a novel, potent angiogenic factor. J Clin Invest 1997; 99: 2691-2700.

34. Pyziak L, Stasikowska-Kanicka O, Danilewicz M, Wagrowska-Danilewicz M. Immunohistochemical analysis of mast cell infiltrates and microvessel density in oral squamous cell cersinoma. Pol J Pathol 2013; 64: 276-280.

35. Kouhsoltani M, Halimi M, Dibazar S. A positive correlation between immunohistochemical expression of CD31 and mast cell tryptase in odontogenic tumors. Pol J Pathol 2015; 66: 170-175.

36. Białas M, Dyduch G, Szpor J, et al. Microvascular density and mast cells in benign and malignant pheochromocytomas. Pol J Pathol 2012; 63: 235-242.

37. Souza LR, Fonseca-Silva T, Santos C, et al. Association of mast cell, eosinophil leucocyte and microvessel densities in actinic cheilitis and lip squamous cell carcinoma. Histopathology 2010; 57: 796-805.

38. Göksu Erol AY. Mast Hücrelerinin Kanser ve Anjiyogenezde Yeni Tanımlanan Rolleri. Van Tıp Dergisi 2013; 20: 189-193.

\section{Address for correspondence}

Şeyhmus Kaya

Department of Pathology

Gazi Yaşargil Education and Research Hospital

Diyarbakır, 21010 Turkey

tel.: $+904122580060 / 3016$

fax: +904122580047

e-mail: drseyhmuskaya21@gmail.com 